\title{
Prevalence and Antimicrobial Resistance of Foodborne Pathogens in Sentinel Dairy Farms
}

\author{
S. A. Baluka, L.N. Musisi, L. S. Y. Buyinza, and F. Ejobi
}

\section{ABSTRACT}

Dairy cattle are common carriers of important foodborne pathogens. Escherichia coli, Salmonella and Campylobacter jejuni are among the commonest causes of foodborne diseases. The high prevalence of microbial infections is escalating antimicrobial usage in human health and for growth promotion and prophylaxis in animal health. Overuse of antimicrobials is increasing antimicrobial residues in animal source foods and accelerating antimicrobial resistance. The study collected 184 samples from 33 dairy farms and assessed prevalence of Escherichia coli, Salmonella and Campylobacter jejuni and their AMR. Sample inoculation for bacterial isolation was by agar surface streaking method and broth dilution. Escherichia coli was isolated on Chromogenic Coliform agar at $37^{\circ} \mathrm{C}$ for 24 hour forming dark blue colonies confirmed by Indole, Methyl Red, VogesProskauer and Citrate biochemical tests. Escherichia coli antimicrobial susceptibility testing was done by single disc diffusion method against eight standard antibiotics. Sensitive, Intermediate and Resistant system was used for reporting antimicrobial susceptibility testing results. Escherichia coli was isolated in $\mathbf{2 1 . 7 \%}$ samples, Campylobacter jejuni and Salmonella were absent. Escherichia coli was isolated in fecal samples from $48.5 \%$ of study farms, $\mathbf{5 6 . 9 \%}$ of fecal and $\mathbf{4 . 8 \%}$ of water samples and not isolated in all milk samples tested. All Escherichia coli isolates were susceptible to gentamycin, ciprofloxacin, cefoxitin and cefotaxime but 9 were resistant to ampicillin, oxacillin, ceftazidime, and ceftriaxone, produced 4 penicillinase and 1 beta-lactamase while 4 didn't exhibit any specific resistance mechanism. Aminoglycosides, quinolones, and furans showed no resistance. When stratified by sample, 7 fecal Escherichia coli isolates showed resistance compared to 2 water isolates. All fecal and water isolates were resistant to oxacillin. The majority of Beta-lactamase and penicillinase producing isolates were from fecal samples. Oxacillin was widely resisted hence it should not be used in routine treatment of bacterial infections to avoid treatment failures. All Escherichia coli isolates were susceptible to gentamycin, ciprofloxacin, cefoxitin and cefotaxime, 9 were resistant to ampicillin, oxacillin, ceftazidime, and ceftriaxone, produced 4 penicillinase and 1 beta-lactamase. Aminoglycosides, quinolones, and furans showed no resistance. There is a need to conduct continuous professional development training programmes for veterinarians and veterinary paraprofessionals to promote prudent use of antimicrobials. Access and use of gentamycin, ciproflaxacin, cefoxitin and cefotaxime by dairy farmers and unqualified people should be restricted to prevent or delay resistance to these four.

Keywords: Antimicrobial, Dairy, Foodborne, Resistance, Susceptibility.
Submitted : August 24, 2021

Published : September 29, 2021

ISSN: $2684-1827$

DOI: $10.24018 /$ ejfood.2021.3.5.364

\section{S. A. Baluka*}

College of Veterinary Medicine, Animal Resources \& Biosecurity, Makerere University, Uganda. (e-mail: sbaluka3@gmail.com)

L.N. Musisi

College of Veterinary Medicine, Animal Resources \& Biosecurity, Makerere University, Uganda. (e-mail: mnlubowa@gmail.com)

L. S. Y. Buyinza

College of Veterinary Medicine, Animal Resources \& Biosecurity, Makerere University, Uganda. (e-mail: blameka1@yahoo.com)

F. Ejobi

College of Veterinary Medicine, Animal Resources \& Biosecurity, Makerere University, Uganda.

(e-mail: ejobifrancis@gmail.com)

*Corresponding Author

\section{INTRODUCTION}

Foodborne diseases (FBDs) are a challenge for both developed and developing countries [2] and are a leading cause of illness and death in developing countries [7]. Bacteria such as Escherichia coli (E. coli), Salmonella and Campylobacter jenuni (C. jenuni) are among the commonest causes of gastrointestinal diseases in sub-Saharan Africa [3] and have been associated with foodborne diseases [23]. Dairy cattle are common carriers of these important foodborne pathogens [19], [11], [12]. The environmental load of Campylobacter in cattle manure is as important as the consumption of raw or unpasteurized milk [5].
The increasing prevalence of microbial infections is escalating the use of antimicrobial agents in human and animal health. In addition, modern food production such as dairy farming encourages use of large quantities of antimicrobial agents for growth promotion and prophylaxis [17], [5], [22]. Over reliance on antimicrobial agents is accelerating the levels of antimicrobial residues in foods of animal origin and the emergence of antimicrobial resistance. The presence of high levels of antimicrobial residues in animal source foods such as milk undermine food safety and the consequent antimicrobial resistance (AMR) is an emerging challenge in developing countries [6]. Antimicrobial resistance increases healthcare expenditures 
in human and animal health care besides morbidity and mortality [1], [24].

This study assessed the prevalence, antimicrobial susceptibility (AS) and resistance profiles of important foodborne pathogens namely Campylobacter jejuni, Escherichia coli and Salmonella in sentinel dairy farms. The findings have public health implications and will aid formulation of policies to guide dairy farmers on the prudent use of antimicrobial agents [16], [8] so as to prevent antimicrobial resistance.

\section{MATERIALS AND MeTHODS}

\section{A. Institutional Review Board Approval}

The study protocol was reviewed and granted a waiver by the research ethics and animal use committee at the College of Veterinary Medicine, Animal Resources and Biosecurity, Makerere University. The researchers explained the purpose and design of the study to all the owners of selected dairy farms, and they gave their informed consent before participating in the study. The study did not involve use of experimental animals.

\section{B. Study Design and Data Collection}

Repeated cross-sectional studies were conducted over a period of one year from June 2018 to June 2019. Samples were collected from 33 dairy farms in nine parishes (Bulijjo, Ddundu, Kabembe, Kiyonga, Kyampisi, Nanga, Namengo and Namuyenje from three Sub-counties (Kimenyede, Kyampisi and Nakisunga), Mukono district. A total of 184 samples were collected comprising milk (57), fecal (65), and environmental (62) samples. Approximately $60 \mathrm{ml}$ of a pooled milk sample was aseptically collected from all the four quarters of the udder of each lactating cow into $100 \mathrm{ml}$ sterile sample collection bottles. The fecal and other environmental samples were also aseptically collected into sterile $50 \mathrm{ml}$ stool collection bottles and $500 \mathrm{ml}$ Ziploc bags (Nunc, UK) respectively. All the samples were transported in a cooler box to the Microbiology Laboratory at the College of Veterinary Medicine, Animal Resources and Biosecurity, Makerere University within 4 hours of collection and immediately processed upon delivery or stored in a refrigerator in case of delay in processing.

\section{Laboratory Analysis}

Samples were received, recorded, and given laboratory identification codes before processing. Sample inoculation for bacterial isolation was by the agar surface streaking method and broth dilution. The controls used included Campylobacter jejuni ATCC 29428, E. coli ATCC 25922 and Salmonella ATCC 13076. Escherichia coli was isolated on Chromogenic Coliform agar (Oxoid, UK) at $37{ }^{\circ} \mathrm{C}$ for $24 \mathrm{~h}$, forming characteristic dark blue colonies. Other coliforms were pink on the same medium.

Confirmatory identification was by the Indole, Methyl Red, Voges-Proskauer and Citrate (IMViC) biochemical tests. Escherichia coli isolates were Indole and Methyl red positive, but VP and Citrate negative. Escherichia coli isolates were tested for antimicrobial susceptibility (AS) using the single disc diffusion method [10], [20] against eight standard antibiotics including gentamycin, ciprofloxacin, ampicillin, oxacillin, cefoxitin, Cefotaxime, Ceftazidine and Ceftriaxone (Liofilchem, Italy).

The antibiotic susceptibility test (AST) results were interpreted and reported as either sensitive (S), intermediate (I) or resistant (R) according to the CLSI / NCCLS (2005) interpretive chart (SIR system). Table I provides a summary of the detection and confirmatory methods used in the study.

TABLE I: DETECTION AND CONFIRMATORY METHODS USED IN THE STUDY

\begin{tabular}{|c|c|c|}
\hline $\begin{array}{c}\text { Target } \\
\text { Bacteria }\end{array}$ & Method & Confirmation \\
\hline E. coli & $\begin{array}{l}\text { Agar streaking } \\
\text { (Quadrant) }\end{array}$ & $\begin{array}{c}\text { Indole, Voges Proskauer, } \\
\text { Methyl red and Citrate } \\
\text { utilization }\end{array}$ \\
\hline $\begin{array}{l}\text { Salmonella } \\
\text { spp. }\end{array}$ & $\begin{array}{l}\text { Pre-enrichment, } \\
\text { enrichment, and } \\
\text { Surface streaking }\end{array}$ & $\begin{array}{l}\text { TSI, Urease production and } \\
\text { Citrate utilization }\end{array}$ \\
\hline $\begin{array}{l}\text { Campylobac } \\
\text { ter jejuni }\end{array}$ & $\begin{array}{l}\text { Pre-enrichment, } \\
\text { enrichment, and } \\
\text { surface streaking }\end{array}$ & $\begin{array}{c}\text { Gram staining, Oxidase test, } \\
\text { Motility testing and Hippurate } \\
\text { hydrolysis }\end{array}$ \\
\hline
\end{tabular}

\section{RESULTS AND DISCUSSION}

\section{A. Background Information and Demographics}

Out of 186 samples collected from 33 study farms, only E. coli was isolated in $40(21.7 \%)$ samples. Campylobacter jejuni and Salmonella were absent. That is, were not isolated from any of the samples tested. Escherichia coli was isolated in $56.9 \%(37 / 65)$ of fecal and $4.8 \%(3 / 62)$ of water samples (Table II). E. coli was not isolated in all the 57 milk samples tested. Out of the 33 study farms, 16 (48.5\%) had $E$. coli isolated from fecal samples. One farm had E. coli isolated from both fecal and water samples. Dundu parish had the highest number of isolates, while the least number of isolates were recorded from Kiyonga parish (Table II).

TABLE II: PREVALENCE OF ESCHERICHIA COLI IN MILK, FECAL AND ENVIRONMENTAL SAMPLES TESTED

\begin{tabular}{|c|c|c|c|c|c|c|}
\hline Sub-county & $-\mathrm{N}-$ & $\begin{array}{c}\#+\mathrm{ve} \\
\%\end{array}$ & $\begin{array}{c}\text { \#Fecal } \\
\%\end{array}$ & \#Milk \% & $\begin{array}{c}\text { \#water } \\
\%\end{array}$ & $\begin{array}{c}\mathrm{p}- \\
\text { value }\end{array}$ \\
\hline Kimenyede & 90 & $\begin{array}{c}30 \\
(33.3)\end{array}$ & $\begin{array}{c}10 \\
(33.3)\end{array}$ & $\begin{array}{c}10 \\
(33.3)\end{array}$ & $\begin{array}{c}10 \\
(15.9)\end{array}$ & 1.00 \\
\hline Kyampisi & 390 & $\begin{array}{c}115 \\
(29.5)\end{array}$ & $\begin{array}{c}45 \\
(39.1)\end{array}$ & $\begin{array}{c}32 \\
(27.8)\end{array}$ & $\begin{array}{c}45 \\
(71.4)\end{array}$ & 0.46 \\
\hline Nakisunga & 78 & $\begin{array}{c}26 \\
(33.3)\end{array}$ & $\begin{array}{c}10 \\
(38.5)\end{array}$ & $\begin{array}{c}8 \\
(30.8)\end{array}$ & $\begin{array}{c}8 \\
(12.7)\end{array}$ & 1.00 \\
\hline Total & 558 & $\begin{array}{c}171 \\
(30.7) \\
\end{array}$ & $\begin{array}{c}65 \\
(38.0) \\
\end{array}$ & $\begin{array}{c}50 \\
(29.2) \\
\end{array}$ & $\begin{array}{c}56 \\
(32.7) \\
\end{array}$ & \\
\hline
\end{tabular}

Kawungu parish had the highest E. coli prevalence $60 \%$ $(18 / 30)$ in Kimenyede Sub-county, Ddundu parish had the highest E. coli prevalence $45 \%(52 / 115)$ in Kyampisi Subcounty while Namuyenje was the only parish studied from Nakisunga (Table III).

The study area was peri-urban, every household had access to a pit latrine or flash toilet and is socio-culturally known to discourage open defecation which probably explains the absence of Campylobacter jejuni and Salmonella. All the forty E. coli isolates were susceptible to gentamycin, ciproflaxacin, cefoxitin and cefotaxime indicating that these antimicrobial agents are still effective for treating $E$. coli related infections hence should be used judiciously to prevent or delay resistance. 
TABLE III: PREVALENCE OF ESCHERICHIA COLI IN STUDY DAIRY FARMS BY PARISH

\begin{tabular}{cccccccc}
\multicolumn{8}{c}{ TABLE III: PREVALENCE OF ESCHERICHIA COLI IN STUDY DAIRY FARMS BY PARISH } \\
\hline Sub-county & Parish & $\mathrm{N}$ & $\%$ & \multicolumn{1}{c}{ Fec. } & Milk & water & p-value \\
\hline Kimenyede (30) & Kawungu & 54 & $18(60.0)$ & $6(33.3)$ & $6(33.3)$ & $6(33.3)$ & 1.0 \\
& Nanga & 36 & $12(40.0)$ & $4(33.3)$ & $4(33.3)$ & $4(33.3)$ & 1.0 \\
& Bulijjo & 72 & $24(20.9)$ & $8(33.3)$ & $8(33.3)$ & $8(33.3)$ & 1.0 \\
& Ddundu & 156 & $52(45.2)$ & $19(36.5)$ & $14(26.9)$ & $19(36.5)$ & 1.0 \\
Kyampisi (115) & Kabembe & 36 & $12(10.4)$ & $4(33.3)$ & $4(33.3)$ & $4(33.3)$ & 1.0 \\
& Kiyonga & 18 & $6(5.2)$ & $2(33.3)$ & $2(33.3)$ & $2(33.3)$ & 1.0 \\
& Kyampisi & 108 & $21(18.3)$ & $12(57.1)$ & $4(19.1)$ & $5(23.8)$ & 0.03 \\
Nakisunga (26) & Namuyenje & 78 & $26(100.0)$ & $10(38.5)$ & $8(30.8)$ & $8(30.8)$ & 1.0 \\
\hline
\end{tabular}

\section{B. Antimicrobial Susceptibility (AST) of Escherichia coli} Isolates

Overall, $12.58 \%$ of the isolates were resistant to Oxacillin followed by Ampicillin at $2.2 \%$. Only $0.31 \%$ of the isolates were resistant to Ceftazidime and Ceftriaxone (Fig. 1).

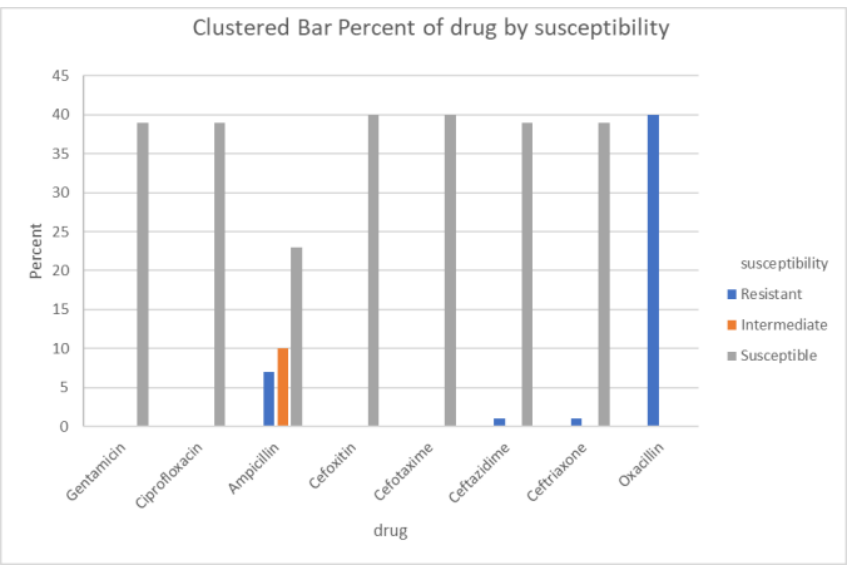

Fig. 1. Overall Escherichia coli resistance by study antibiotic.

Isolates from fecal samples were generally more resistant compared to those isolated from water samples (Fig. 2).

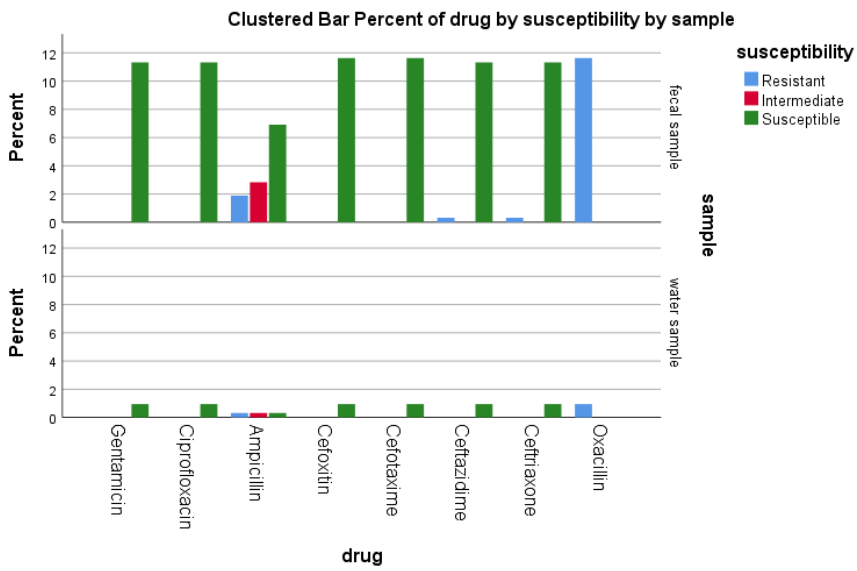

Fig. 2. Stratified Escherichia coli Resistance by Study Antibiotic.

\section{Resistance and Susceptibility Pattern of Escherichia coli Isolates Detected by VITEK 2 AES}

Nine (9) Escherichia coli isolates showed resistance to ampicillin, oxacillin, ceftazidime and ceftriaxone, with four (4) exhibiting penicillinase producing potential, One (1) producing beta lactamase enzyme, while four (4) didn't exhibit any specific mechanism of resistance. There was no resistance exhibited against aminoglycosides, quinolones, and furans (Fig. 3).

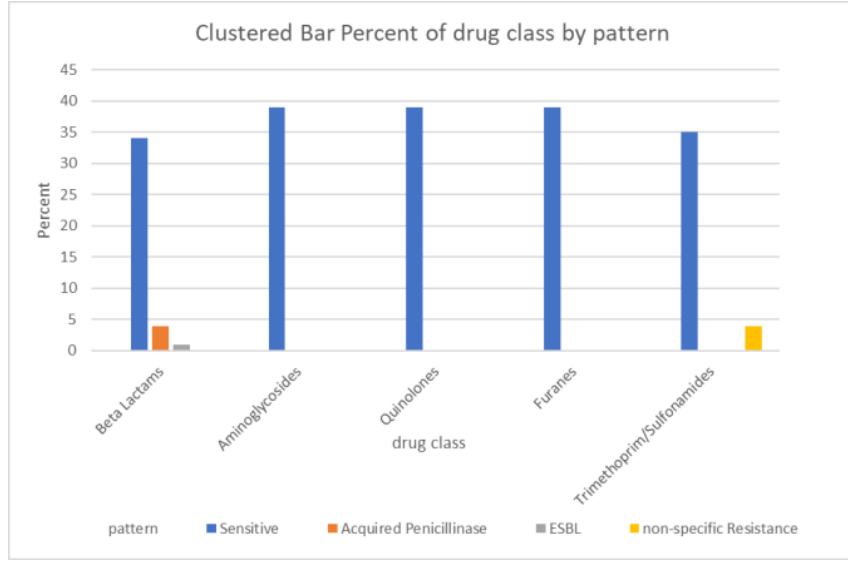

Fig. 3. Overall Escherichia coli resistance by class of study antibiotics.

When stratification by sample i.e., fecal and water was done, seven (7) E. coli isolates from fecal samples showed resistance to the test antibiotics compared to only two (2) from water samples that showed resistance. Majority of Beta lactamase and penicillinase producing isolates were from fecal samples.

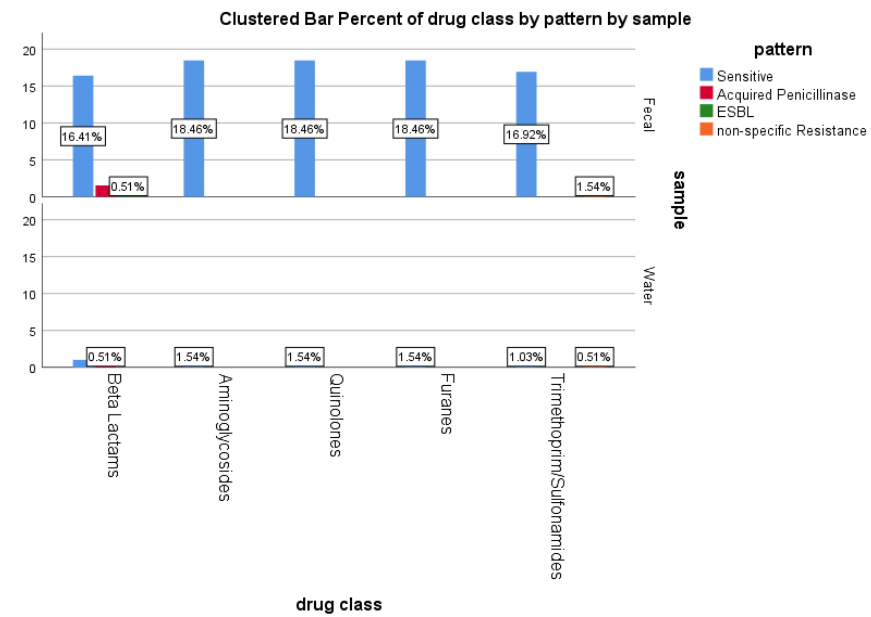

Fig. 4. Stratified Escherichia coli resistance by class of study antibiotics.

Foodborne bacterial pathogens, opportunistic pathogens, and commensals such as Escherichia coli like other bacteria are capable of developing antimicrobial resistance [21]. The findings from this study are important and are of value to efforts towards improving public health by preventing antimicrobial resistance. Even commensal bacteria in food producing animals are considered an important reservoir of antibiotic resistance genes [13]. Additionally, increases in antimicrobial resistance in Escherichia coli have been paralleled by increasing incidence of Escherichia coli associated sepsis suggesting a possible link between resistance and virulence [9]. 
Humans can become infected by antimicrobial resistant Escherichia coli of animal origin which may cause infections in humans with limited therapeutic options resulting into consequences such as treatment failure besides donating antimicrobial resistance genes to other pathogenic Escherichia coli strains. In humans, Escherichia coli may cause several infections including gastrointestinal tract disorders like diarrhea, urinary tract infections, meningitis, peritonitis, septicemia, and gram-negative bacterial pneumonia [4].

The six isolates that were resistant to both ampicillin $(15 \%)$ and oxacillin $(92.5 \%)$ agree with the earlier findings [14], [15] that multi-drug antimicrobial resistance in Africa is growing. All the isolates, whether isolated from fecal or water samples were resistant to oxacillin hence use of this agent is likely to result into treatment failure. Therefore, oxacillin and ampicillin should not be considered drugs of choice for treating microbial infections particularly oxacillin to which the isolates showed very high resistance.

All Escherichia coli isolates showed very high resistance towards oxacillin. All the forty Escherichia coli isolates were susceptible to gentamycin, ciproflaxacin, cefoxitin and cefotaxime. Oxacillin was widely resisted hence using it in routine treatment of bacterial infections is likely to result into treatment failure. On the other hand, gentamycin, ciproflaxacin, cefoxitin and cefotaxime were still very effective indicating that these antimicrobial agents are still effective for treating Escherichia coli and other bacterial infections and can still serve the purpose in future if they are used prudently to avoid or prevent emergence of antimicrobial resistance thus should be used judiciously to prevent or delay resistance.

Use of antimicrobials in animal production should be restricted globally. Producers should invest in measures involving biosecurity, genetics, health care and farm management, animal welfare and nutrition to prevent diseases and minimize the use of antimicrobials [18].

\section{CONCLUSION}

Escherichia coli demonstrated very high resistance towards oxacillin. Hence use of oxacillin for routine clinical treatment of bacterial infections should be discouraged to avoid treatment failure. Continuing Professional Development (CPD) Educational programmes should be implemented for Veterinarians and Veterinary Paraprofessionals (VPPs) as well as farmers to promote prudent use of antimicrobial agents. The government of Uganda should restrict access and use of gentamycin, ciproflaxacin, cefoxitin and cefotaxime by the farmers to prevent resistance to these antibiotics that are still effective for treating bacterial infections.

\section{ACKNOWLEDGEMENTS}

The authors appreciate Mukono district veterinary office and the staff for their support and participation, dairy farmers for their cooperation and Carnegie Corporation of New York for funding this study through the Directorate of Research and Graduate Training, Makerere University.
This work was supported by the Carnegie Post-doctoral research project "Nurturing Emerging Research Leaders through Postdoctoral Training at Makerere University", Grant Number G-16-54068 years 2017-2019.

\section{CONFLICT OF INTEREST}

The authors have no conflict of interest, whether financial, technical, or institutional.

\section{REFERENCES}

[1] A. Aidara-Kane, "Containment of antimicrobial resistance due to use of antimicrobial agents in animals intended for food," World Health Organization perspectives. Review Scientific Technical (Office International Epizootics, 31(1), pp. 277-289, April 2012 https://pubmed.ncbi.nlm.nih.gov/22849282/.

[2] D. T. Da Cuhna, E. Stedefeldt and V. V. De Rosso, "Perceived risk of foodborne diseases by school food handlers and principals. The influence of frequent training," Journal of Food Safety, 32, pp. 219$225 \quad$ February https://onlinelibrary.wiley.com/doi/epdf/10.1111/j.17454565.2012.00371.x.

[3] S. M. Fletcher, D. Stark, J. Ellis, "Prevalence of gastrointestinal pathogens in sub-Saharan Africa: Systematic review and metaanalysis," Journal of Public Health, 3, pp. 163-167. June 2011 https://pubmed.ncbi.nlm.nih.gov/28299071/.

[4] A. M. Haemmerum and O. E. Heuer, "Human health hazards from antimicrobial resistant Escherichia coli of animal origin," Clinical Infectious Diseases, 48 (7), pp. 916-921. April 2009. https://pubmed.ncbi.nlm.nih.gov/19231979/.

[5] Hakkinen Maejaana et al. "Prevalence of Campylobacter species in cattle in Finland and antimicrobial susceptibilities of Bovine Campylobacter jejuni strains," Applied and Environmental Microbiology, 73(10), pp. 3232-3238. May 2007. https://pubmed.ncbi.nlm.nih.gov/17369335/.

[6] C. A. Hart and S. Kariuki, "Antimicrobial resistance in developing countries," British Medical Journal, 317(17), pp. 647-650. September 1998. https://pubmed.ncbi.nlm.nih.gov/9727995/.

[7] N. Hassan Ali, A. Farooqui, A. Khan, A. Y. Khan and S. U. Kazmi, "Microbiological contamination of raw meat and its environment in retail shops in Karachi," Pakistan Journal of Infections in Developing $\begin{array}{llll}\text { Countries, } & 4(6), & \text { pp. 382-388. June } 2010 .\end{array}$ https://pubmed.ncbi.nlm.nih.gov/20601790/.

[8] J. Hur, C. Jawale, and J. H. Lee, "Antimicrobial resistance of Salmonella isolated from food animals: A review," Food Research International, 45(2), pp. 819-830. March 2012. https://europepmc.org/article/agr/ind44696333.

[9] J. R. Johnson, A. M. Kuskowski, A. Gajewski, D. F. Sahm, and J. A. Karlowsky, "Virulence characteristics and Phylogenetic background of multi-drug resistant and antimicrobial susceptible clinical isolates of Escherichia coli from across the United States 2000-2001," The Journal of Infectious Diseases, 190(10), pp. 1739-1744. November 2004. https://academic.oup.com/jid/article/190/10/1739/2191466.

[10] J, H. Jorgensen and J. D. Turnidge, "Susceptibility test methods: Dilution and disk diffusion methods," In Manual of Clinical Microbiology (Vol.1, $8^{\text {th }}$ Edition). Patrick R. Murray, Ellen JO Baron, James H Jorgensen, Michael A Pfaller and Robert H Yolken (Eds). ASM Press, Washington D.C. 2003: 1119-1120. https://baixardoc.com/documents/manual-of-clinical-microbiologyshafinewaz-rph-5cfac988162ea.

[11] M. H. Josefsen, A. K. Bhunia, E. O. Engvall, M. S. Fachmann, J. Hoorfar, "Monitoring Campylobacter in the poultry production chain from culture to genes and beyond," Journal of Microbiology Methods, 112, pp. 118-125. May 2015. https://europepmc.org/article/med/25771343.

[12] N. O. Kaakoush, N. Castaño-Rodríguez, H. M. Mitchell, S. M. Man, "Global epidemiology of Campylobacter infection," Clinical $\begin{array}{llll}\text { Microbiology Review, 28(3), 687-720 July } 2015 . & .\end{array}$ https://pubmed.ncbi.nlm.nih.gov/26062576/.

[13] P. Knezecic and O. Petrovic, "Antibiotic resistance of commensal Escherichia coli of food producing animals from three vojvodinian farms, Serbia," International Journal of Antimicrobial Agents, 31(4), pp. 360-363. April 2008 https://pubmed.ncbi.nlm.nih.gov/18162377/.

[14] I. N. Okeke, O. A. Aboderin, D. K. Byarugaba, K. K. Ojo and J. A. Opintan, "Growing problem of multidrug resistant enteric pathogens 
in Africa," Clinical Microbiology Review. Emerging Infectious Diseases, 13 (11), pp. 1640-1646 November 2007. https://www.ncbi.nlm.nih.gov/pmc/articles/PMC3375797/.

[15] S. Omulo, S. M. Thumbi, M. K. Njenga et al. "A review of 40 years of enteric antimicrobial resistance research in Eastern Africa: what can be done better?" Antimicrobial Resistance and Infection Control, 4(1), January 2015.

https://aricjournal.biomedcentral.com/articles/10.1186/s13756-0140041-4.

[16] F. M. Sanchez-vargas, M. A. Abu-El-Haija, O. G. Gomez-Duarte, "Salmonella infections: An up-date on epidemiology, management and prevention," A Review. Travel Medicine and Infectious Diseases, 9 (6), pp. 263-277, November 2011. https://pubmed.ncbi.nlm.nih.gov/22118951/.

[17] S. Schwarz, C. Kehrenberg and T. R. Walsh, "Use of antimicrobial agents in Veterinary Medicine and food animal production," Review Article. International Journal of Antimicrobial Agents, 17(6), pp. 431 437, June 2001. https://pubmed.ncbi.nlm.nih.gov/11397611/.

[18] C. H. M. Smits, D. Li, J. F. Patience and L. A. den Hartog, “Animal nutrition strategies and options to reduce the use of antimicrobials in animal production," FAO Animal Production and Health Paper Number, 184, 2021. Rome, FAO. https://doi.org/10.4060/cb5524en.

[19] K. Stanley and K. Jones, "Cattle and sheep farms as reservoirs of Campylobacter," Journal of Applied Microbiology, 94 Supplement 104S-113S, 2003. https://pubmed.ncbi.nlm.nih.gov/12675942/.

[20] K. Syal, M. Mo, H. Yu, R. Iriya, W. Jing, S. Guodong, S. Wang, T. E. Grys, S.E. Haydel and N. Tao, "Current and Emerging techniques for antibiotic susceptibility tests," Theranostics, 7 (7), pp. 1795-1805 April 2017. https://pubmed.ncbi.nlm.nih.gov/28638468/.

[21] M. Teuber, "Veterinary Use and Antibiotic Resistance. Current Opinions in Microbiology," 4(5), pp. 493-499 October 2001. https://pubmed.ncbi.nlm.nih.gov/11587923/.

[22] Center for Disease Control (CDC), United States Department of Health and Human Services Centers for Disease Control and Prevention. Antibiotic resistance threats in the United States Atlanta, GA. A report, 2019. https://www.cdc.gov/drugresistance/pdf/threatsreport/2019-ar-threats-report-508.pdf.

[23] United States Food and Drug Administration "Foodborne pathogenic microorganisms and natural toxins handbook". Edited by Keith A. Lampel, Sulfian Al-Khaldi and Susan Mary Cahill. The bad bug book Second Edition. 2012, 2017. https://www.fda.gov/food/foodbornepathogens/bad-bug-book-second-edition.

[24] World Health Organization, In collaboration with Food and Agriculture Organization of the United Nations (FAO), and World Organization for Animal Health (OIE). Integrated Surveillance of antimicrobial resistance in foodborne bacteria. Application of a one health approach. 2017. Guidance from the WHO Advisory Group on Integrated Surveillance of Antimicrobial Resistance (AGISAR) ISBN 978-92-4-151241-1.

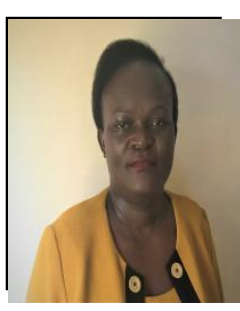

Dr. Sylvia Angubua Baluka was born on $23^{\text {rd }}$ April 1973 in Budaka Eastern Uganda.

She is a graduate of BVM, MBA, PHD (MUK), PGD-HRM (UMI), MSFS (MSU).

She researches and teaches in the fields of transboundary animal diseases (TADs), Food Safety, Veterinary Epidemiology and Animal Health Economics.

Dr. Baluka is a member of; the International Society for Veterinary Epidemiology and Economics, Uganda Veterinary Association, and a Certified Project Management Professional (PMP) and Member Project Management Institute. 